\title{
Subclinical changes in serum creatinine and mortality after coronary artery bypass grafting
}

\author{
Daniel A. Tolpin, MD, ${ }^{\mathrm{a}, \mathrm{c}}$ Charles D. Collard, MD, ${ }^{\mathrm{a}, \mathrm{c}}$ Vei-Vei Lee, MS, ${ }^{\mathrm{b}}$ Salim S. Virani, MD, ${ }^{\mathrm{d}}$ \\ Paul M. Allison, MD, ${ }^{e}$ MacArthur A. Elayda, MD, PhD, ${ }^{\mathrm{b}}$ and Wei Pan, $\mathrm{MD}^{\mathrm{a}, \mathrm{c}}$
}

\begin{abstract}
Background: Changes in postoperative serum creatinine levels have been used to define acute renal injury in patients undergoing cardiac surgery with cardiopulmonary bypass. It remains unclear, however, whether subclinical increases in serum creatinine that do not meet current Acute Kidney Injury Network or RIFLE (risk, injury, failure, loss, and end-stage kidney disease) criteria for acute renal injury are predictive of mortality after cardiac surgery.
\end{abstract}

\begin{abstract}
Methods: Multivariate logistic regression was performed in a retrospective cohort of 3914 consecutive patients undergoing primary, isolated coronary artery bypass grafting with cardiopulmonary bypass to determine whether postoperative serum creatinine change independently predicts 30-day all-cause mortality in patients with normal renal function and with varying levels of preoperative renal insufficiency. To control further for selection bias, multivariate logistic regression was performed on a propensity-matched cohort $(n=2042)$ to determine whether subclinical increases in serum creatinine predict mortality.
\end{abstract}

Results: Negative change in serum creatinine was associated with reduced 30-day all-cause mortality. Even subclinical increases in serum creatinine were associated with increased mortality relative to patients with negative changes in serum creatinine (odds ratio, 3.93; 95\% confidence interval, 1.68-9.22; $P<.01$ ). After propensity matching, subclinical increases in serum creatinine were still associated with increased mortality (odds ratio, $4.13 ; 95 \%$ confidence interval, $1.37-12.45 ; P=.01)$.

Conclusions: Subclinical increases in serum creatinine that do not meet acute renal injury criteria are independently associated with 30-day all-cause mortality in patients with normal renal function or preoperative renal insufficiency undergoing coronary artery bypass grafting. (J Thorac Cardiovasc Surg 2012;143:682-8)

Supplemental material is available online.

Preoperative renal insufficiency (RI) has been shown to be associated with cardiac surgical morbidity and mortality. As a result, numerous perioperative risk stratification models, such as the EuroSCORE, Society of Thoracic Surgeons score, and Cleveland Clinic score, incorporate preoperative serum creatinine to predict the risk of adverse outcomes

\footnotetext{
From the Divisions of Cardiovascular Anesthesiology ${ }^{\mathrm{a}}$ and Biostatistics and Epidemiology, ${ }^{b}$ the Texas Heart Institute, St Luke's Episcopal Hospital, Houston, Tex; the Department of Anesthesiology ${ }^{\mathrm{c}}$ and the Michael E. DeBakey Veterans Affairs Medical Center Health Services Research and Development Center of Excellence, ${ }^{\mathrm{d}}$ Baylor College of Medicine, Houston, Tex; Chemistry, Coagulation and Blood Donor Center, ${ }^{e}$ Department of Pathology, St Luke's Episcopal Hospital, Houston, Tex.

Disclosures: Authors have nothing to disclose with regard to commercial support. Received for publication March 18, 2011; revisions received Aug 29, 2011; accepted for publication Sept 26, 2011; available ahead of print Nov 7, 2011.

Address for reprints: Wei Pan, MD, Assistant Professor, Division of Cardiovascular Anesthesiology at the Texas Heart Institute, St Luke's Episcopal Hospital, 6720 Bertner Ave, Room 0520, Houston, TX 77030 (E-mail: wpan@ heart.thi.tmc.edu). 0022-5223/\$36.00

Copyright (c) 2012 by The American Association for Thoracic Surgery doi:10.1016/j.jtcvs.2011.09.044
}

after surgery. ${ }^{1,2}$ In contrast, few data exist to determine whether the postoperative change in serum creatinine is independently associated with mortality after cardiac surgery in patients with normal preoperative renal function (RF) and varying degrees of preoperative RI. ${ }^{3-5}$ Moreover, it remains unclear whether subclinical changes in postoperative serum creatinine levels, changes that do not meet current diagnostic criteria for acute kidney injury (AKI), as defined by Acute Kidney Injury Network $(\mathrm{AKIN})^{6}$ or $\mathrm{RIFLE}^{7}$ (risk, injury, failure, loss, and endstage kidney disease) criteria (Table E1), may still affect outcomes after cardiac surgery.

Recently, Lassnigg and colleagues ${ }^{3,4}$ found that small changes in postoperative serum creatinine levels are associated with increased mortality after cardiac surgery. Their study did not control for varying degrees of preoperative RI, however, and was potentially confounded by the inclusion of multiple types of cardiothoracic operations. Because postoperative serum creatinine levels vary with baseline RF, it is important to assess change in serum creatinine as a biomarker across the spectrum of preoperative RF. In a retrospective cohort $(\mathrm{n}=3914)$ of patients undergoing primary, isolated coronary artery bypass grafting (CABG) with cardiopulmonary bypass (CPB) at a single institution, we 


$$
\begin{aligned}
& \text { Abbreviations and Acronyms } \\
& \text { AKI }=\text { acute kidney injury } \\
& \text { AKIN }=\text { Acute Kidney Injury Network } \\
& \text { CABG }=\text { coronary artery bypass grafting } \\
& \text { CI }=\text { confidence interval } \\
& \text { CPB }=\text { cardiopulmonary bypass } \\
& \text { GFR }=\text { glomerular filtration rate } \\
& \text { OR }=\text { odds ratio } \\
& \text { RF } \quad \text { renal function } \\
& \text { RI }=\text { renal insufficiency } \\
& \text { RIFLE }=\text { risk, injury, failure, loss, and end-stage } \\
& \text { kidney disease }
\end{aligned}
$$

investigated whether subclinical postoperative serum creatinine change independently predicts 30-day all-cause mortality in patients with normal RF and with varying levels of preoperative RI.

\section{MATERIALS AND METHODS \\ Study Subjects}

A retrospective cohort study was performed on all consecutive patients $(\mathrm{n}=3914)$ undergoing primary, isolated CABG with CPB between January 2002 and January 2008 at the Texas Heart Institute, St Luke's Episcopal Hospital. Institutional review board approval was obtained. Patients were classified into 4 groups according to preoperative RF by applying the abbreviated Modification of Diet in Renal Disease study equation ${ }^{8}$ : normal was a glomerular filtration rate (GFR) of at least $90 \mathrm{~mL} / \mathrm{min}$ per $1.73 \mathrm{~m}^{2}$ ( $\mathrm{n}=714$ ); mild RI was a GFR of 60 to $89 \mathrm{~mL} / \mathrm{min}$ per $1.73 \mathrm{~m}^{2}$ ( $\mathrm{n}=2085$ ); moderate RI was a GFR of 30 to $59 \mathrm{~mL} / \mathrm{min}$ per $1.73 \mathrm{~m}^{2}$ $(\mathrm{n}=951)$; and severe RI was a GFR less than $30 \mathrm{~mL} / \mathrm{min}$ per $1.73 \mathrm{~m}^{2}$ $(\mathrm{n}=164)$. Patients undergoing repeat sternotomy or CABG combined with other cardiac procedures (atrial septal defect repair, valve repair or replacement, and so on) were excluded from the study. Patients receiving preoperative dialysis were also excluded.

\section{Data Collection}

Patient demographic characteristics, risk factors, and serum creatinine levels were obtained from the Texas Heart Institute cardiac surgical database. Preoperative serum creatinine levels were defined as the highest creatinine level within 48 hours before surgery. Postoperative serum creatinine levels were defined as the peak serum creatinine level within 48 hours after surgery. Change in serum creatinine was defined as the difference between the peak postoperative and preoperative serum creatinine levels. The measured end point was 30-day all-cause mortality.

\section{Statistical Analyses}

All statistical analyses were performed with SAS statistical software (version 9.1; SAS Institute, Cary, NC) by the Division of Biostatistics and Epidemiology, Texas Heart Institute, Houston, Texas. Continuous variables were expressed as the mean $\pm \mathrm{SD}$, and categoric (frequency) variables were expressed as percentages. Univariate logistic regression analyses were initially conducted to evaluate whether there were between-group differences in patient preoperative demographic characteristics, risk factors, and preoperative medications (Table 1).

To assess the influence of preoperative baseline RF on perioperative mortality, multivariate stepwise logistic regression was first performed on all patients to determine whether the severity of preoperative RI was independently associated with 30-day all-cause mortality after CABG with CPB. Multivariate stepwise logistic regression was then performed on each group to determine whether the postoperative change in serum creatinine as a continuous variable was independently associated with 30 day all-cause mortality. Only those variables statistically significant at a $P$ value less than .05 were retained within the final model. Odds ratios (ORs), corresponding $95 \%$ confidence intervals (CIs), and associated $P$ values are reported.

To categorize further the impact of subclinical changes in serum creatinine, patients were then divided into 3 groups: Group A consisted of patients with a negative change in serum creatinine $(\leq-0.1 \mathrm{mg} / \mathrm{dL}$; $\mathrm{n}=1762$ ); group $\mathrm{B}$ consisted of patients with postoperative $\mathrm{AKI}$ as defined by $\mathrm{AKIN}^{6}$ or $\mathrm{RIFLE}^{7}$ criteria (change in serum creatinine $\geq 0.3 \mathrm{mg} / \mathrm{dL}$ or $\geq 150 \%$ increase from baseline; $n=472$ ); and group $C$ consisted of patients with a subclinical increase in serum creatinine that did not meet the $\mathrm{AKIN}^{6}$ or $\mathrm{RIFLE}^{7}$ AKI criteria (change in serum creatinine 0-0.2 $\mathrm{mg} / \mathrm{dL}$ with $<150 \%$ increase in creatinine from baseline; $\mathrm{n}=1494$ ). Stepwise, multivariate logistic regression analysis was then performed to determine an association with 30-day all-cause mortality. Finally, in an attempt to control further for selection bias and to determine whether a subclinical increase in serum creatinine was associated with 30-day all-cause mortality, conditional logistic regression was also performed on a propensity score-matched cohort of group A patients $(n=1021)$ and group $C$ patients $(n=1021)$. Propensity scores for patients in groups A and $C$ were developed by using multivariate logistic regression modeling. A greedy algorithm was used to match cases in group $\mathrm{C}$ with those in group $\mathrm{A}$. The presented algorithm also used the nearest available pair matching method. The matching process was automatically performed by the previously described SAS statistical software. Table 2 contains a list of 31 of the 44 variables used to determine each subject's propensity score. We estimated that with a sample size of 860 patients for each group, the study should have $80 \%$ power to detect significant difference of the mortality between group A and group C. After the propensity matching, patient preoperative demographic characteristics, risk factors, and preoperative medications were compared between groups by McNemar test for categoric variables and by paired $t$ test for continuous variables.

\section{RESULTS}

Eighteen patients were excluded from the analyses because of missing postoperative serum creatinine levels. Table 1 displays patient demographic characteristics and perioperative risk factors for patients with normal RF and patients with mild, moderate, and severe RI. As expected, worsening RF was associated with more preoperative comorbidity. Specifically, patients with severe RI were more likely to be older than 65 years, to require urgent surgery, to have diabetes or hypertension, to have an ejection fraction less than $50 \%$, and to have a diagnosis of congestive heart failure or stroke. In addition, increased severity of $\mathrm{RF}$ was more common among women and was associated with a higher likelihood of receiving medical therapy for comorbid conditions ( $\beta$-blockers and calcium-channel blockers).

Relative to patients with normal preoperative RF, patients with mild preoperative RI did not have an increased 30-day all-cause mortality ( $1.3 \%$ vs $1.4 \%)$. In contrast, both moderate preoperative RI (OR, 2.54; 95\% CI, 1.09-5.89; $P=.03)$ and severe preoperative RI (OR, 5.14; 95\% CI, $2.02-13.06 ; P<.01)$ were independently associated with 
TABLE 1. Perioperative demographic characteristics and risk factors in patients with normal renal function and varying levels of renal insufficiency

\begin{tabular}{|c|c|c|c|c|}
\hline & $\begin{array}{c}\text { Normal RF } \\
(n=714)\end{array}$ & $\begin{array}{c}\text { Mild RI } \\
(\mathbf{n}=\mathbf{2 0 8 5})\end{array}$ & $\begin{array}{l}\text { Moderate RI } \\
(\mathbf{n}=\mathbf{9 5 1})\end{array}$ & $\begin{array}{l}\text { Severe RI } \\
(n=164) \\
\end{array}$ \\
\hline Age $>65 y$ & $13.5 \%$ & $33.1 \% *$ & $38.4 \% *$ & $32.3 \% *$ \\
\hline Female & $18.5 \%$ & $20.6 \%$ & $35.0 \% *$ & $39.6 \% *$ \\
\hline Smoker & $53.5 \%$ & $48.3 \%$ & $48.1 \%$ & $45.7 \%$ \\
\hline Urgent surgery & $24.0 \%$ & $24.8 \%$ & $26.4 \%$ & $31.7 \% *$ \\
\hline Obesity (body mass index $>30 \mathrm{~kg} / \mathrm{m}^{2}$ ) & $40.9 \%$ & $37.7 \%$ & $39.9 \%$ & $38.4 \%$ \\
\hline Diabetes & $41.7 \%$ & $34.2 \% *$ & $42.9 \%$ & $78.7 \% *$ \\
\hline Hypertension & $79.0 \%$ & $80.3 \%$ & $89.3 \% *$ & $92.7 \% *$ \\
\hline Triple-vessel disease & $53.2 \%$ & $55.0 \%$ & $58.4 \% *$ & $59.2 \%$ \\
\hline Left main disease & $24.0 \%$ & $27.0 \%$ & $30.0 \% *$ & $34.2 \% *$ \\
\hline Previous myocardial infarction & $40.3 \%$ & $36.9 \%$ & $36.0 \%$ & $52.4 \% *$ \\
\hline Unstable angina & $43.7 \%$ & $42.8 \%$ & $41.22 \% *$ & $36.0 \%$ \\
\hline Ejection fraction $<50 \%$ & $29.3 \%$ & $30.4 \%$ & $28.3 \%$ & $47.0 \% *$ \\
\hline Valve disease & $4.3 \%$ & $6.5 \% *$ & $8.7 \% *$ & $15.2 \% *$ \\
\hline Congestive heart failure & $13.3 \%$ & $16.5 \% *$ & $26.3 \% *$ & $59.8 \% *$ \\
\hline Transient ischemic attack & $1.8 \%$ & $3.1 \%$ & $4.7 \% *$ & $1.8 \%$ \\
\hline Stroke & $2.0 \%$ & $5.0 \% *$ & $9.9 \% *$ & $14.0 \% *$ \\
\hline Pulmonary disease & $23.5 \%$ & $25.5 \%$ & $31.6 \% *$ & $39.6 \% *$ \\
\hline Peripheral vascular disease & $9.8 \%$ & $14.7 \% *$ & $25.3 \% *$ & $40.2 \% *$ \\
\hline Preoperative intra-aortic balloon pump & $3.5 \%$ & $3.4 \%$ & $4.5 \%$ & $4.3 \%$ \\
\hline Preoperative $\beta$-blocker & $48.7 \%$ & $53.8 \%$ & $57.5 \% *$ & $62.2 \% *$ \\
\hline Preoperative angiotensin-converting enzyme Inhibitor & $44.4 \%$ & $45.0 \%$ & $53.8 \% *$ & $42.1 \%$ \\
\hline Preoperative calcium-channel blocker & $16.7 \%$ & $16.3 \%$ & $22.4 \% *$ & $33.5 \% *$ \\
\hline Preoperative aspirin (INN acetylsalicylic acid) & $62.4 \%$ & $67.1 \% *$ & $64.6 \%$ & $57.3 \%$ \\
\hline Preoperative statin & $56.2 \%$ & $60.9 \% *$ & $63.5 \% *$ & $49.1 \%$ \\
\hline Preoperative clopidogrel bisulfate (INN clopidogrel) & $18.8 \%$ & $22.4 \% *$ & $23.7 \% *$ & $22.0 \%$ \\
\hline Aortic crossclamp time (min, mean $\pm \mathrm{SD}$ ) & $42 \pm 22$ & $43 \pm 24$ & $43 \pm 27$ & $43 \pm 26$ \\
\hline Total bypass time (min, mean \pm SD) & 73. \pm 35 . & $73 \pm 38$ & $74 \pm 36$ & $75 \pm 38$ \\
\hline
\end{tabular}

Except as noted, numbers represent percentages of patients. $R F$, Renal function; $R I$, renal insufficiency. ${ }^{*} P<.05$ relative to patients with normal renal function.

30 -day all cause mortality ( $3.5 \%$ and $11.6 \%$, respectively). Multivariate logistic regression analysis of risk factors for 30-day all-cause mortality is shown in Figure 1.

Multivariate logistic regression was then performed to determine whether the postoperative change in serum creatinine as a continuous variable was independently associated with 30-day all-cause mortality. In patients with normal preoperative RF, change in serum creatinine was independently associated with an increased 30-day all-cause mortality (OR, 6.84; 95\% CI, 2.81-16.63; $P<.01$ ). Change in serum creatinine was also a significant predictor of 30-day allcause mortality in patients with mild preoperative RI (OR, $16.3 ; 95 \% \mathrm{CI}, 7.60-34.97 ; P<.01)$ and moderate preoperative RI (OR, 2.59; 95\% CI, 1.60-4.18; $P<.01$ ). In contrast, change in serum creatinine was not associated with an increased risk of 30-day all cause mortality in patients with severe preoperative RI (OR, 0.88 ; $95 \%$ CI, 0.68 $1.15 ; P=.35$ ). Figure 2 displays the incidence of 30-day all-cause mortality for each level of change in serum creatinine in a combined group of patients with normal RF, mild preoperative RI, and moderate preoperative RI. Patients with a negative change in serum creatinine accounted for $47 \%$ of the patient population who underwent CABG with CPB and had the lowest 30-day all-cause mortality at $0.45 \%(\mathrm{n}=1762)$. A stepwise increase in mortality was observed when the level of change in serum creatinine increased from 0 to $0.4 \mathrm{mg} / \mathrm{dL}$, above which threshold mortality increased exponentially.

To categorize the impact of subclinical changes in serum creatinine, patients were then divided into 3 groups. Group A consisted of patients with a negative change in serum creatinine $(\leq-0.1 \mathrm{mg} / \mathrm{dL} ; \mathrm{n}=1762)$; group $\mathrm{B}$ consisted of patients with postoperative AKI as defined by $\mathrm{AKIN}^{6}$ and RIFLE $^{7}$ criteria (change in serum creatinine $\geq 0.3 \mathrm{mg} / \mathrm{dL}$ or $\geq 150 \%$ increase from baseline; $n=472$ ); and group $C$ consisted of patients with a subclinical increase in serum creatinine that did not meet the $\mathrm{AKIN}^{6}$ or RIFLE ${ }^{7} \mathrm{AKI}$ criteria (change in serum creatinine $0-0.2 \mathrm{mg} / \mathrm{dL}$ with $<150 \%$ increase in creatinine from baseline; $n=1494$ ). The 30-day all-cause mortalities were $0.45 \%$ in group $\mathrm{A}, 1.61 \%$ in group C, and 8.26 in group B. Stepwise, multivariate logistic regression analysis was performed to determine whether 
TABLE 2. Perioperative demographic variables and risk factors in propensity-matched cohorts $(n=2042)$

\begin{tabular}{|c|c|c|c|}
\hline & $\begin{array}{c}\text { Group A } \\
(\mathbf{n}=\mathbf{1 0 2 1})\end{array}$ & $\begin{array}{c}\text { Group C } \\
(\mathbf{n}=\mathbf{1 0 2 1})\end{array}$ & $\begin{array}{c}P \\
\text { value }\end{array}$ \\
\hline Age $>65$ y & $45.5 \%$ & $45.4 \%$ & .93 \\
\hline Female & $23.8 \%$ & $23.0 \%$ & .68 \\
\hline Normal preoperative renal function & $18.4 \%$ & $19.2 \%$ & .90 \\
\hline Mild preoperative renal insufficiency & $62.4 \%$ & $61.6 \%$ & .90 \\
\hline $\begin{array}{l}\text { Moderate preoperative renal } \\
\text { insufficiency }\end{array}$ & $19.2 \%$ & $19.2 \%$ & .90 \\
\hline Smoker & $51.6 \%$ & $48.3 \%$ & .13 \\
\hline Urgent surgery & $23.3 \%$ & $25.0 \%$ & .38 \\
\hline Obesity (body mass index $>30 \mathrm{~kg} / \mathrm{m}^{2}$ ) & $39.6 \%$ & $39.4 \%$ & .93 \\
\hline Diabetes & $35.6 \%$ & $37.2 \%$ & .46 \\
\hline Hypertension & $85.1 \%$ & $84.8 \%$ & .85 \\
\hline Triple-vessel disease & $53.3 \%$ & $53.5 \%$ & .59 \\
\hline Left main disease & $25.2 \%$ & $25.8 \%$ & .76 \\
\hline Previous myocardial infarction & $35.5 \%$ & $36.3 \%$ & .68 \\
\hline Unstable angina & $44.8 \%$ & $42.2 \%$ & .25 \\
\hline Valvular heart disease & $5.9 \%$ & $6.3 \%$ & .71 \\
\hline Congestive heart failure & $15.4 \%$ & $14.2 \%$ & .45 \\
\hline History of transient ischemic attack & $2.6 \%$ & $2.3 \%$ & .66 \\
\hline History of stroke & $5.4 \%$ & $5.2 \%$ & .84 \\
\hline Carotid artery disease & $32.2 \%$ & $32.6 \%$ & .85 \\
\hline Peripheral vascular disease & $13.6 \%$ & $15.3 \%$ & .29 \\
\hline Pulmonary disease & $24.7 \%$ & $25.6 \%$ & .65 \\
\hline Preoperative intra-aortic balloon pump & $1.9 \%$ & $1.8 \%$ & .87 \\
\hline Preoperative $\beta$-blocker & $53.1 \%$ & $51.6 \%$ & .51 \\
\hline Preoperative calcium-channel blocker & $17.0 \%$ & $18.5 \%$ & .39 \\
\hline $\begin{array}{l}\text { Preoperative angiotensin-converting } \\
\text { enzyme inhibitor }\end{array}$ & $47.8 \%$ & $49.66 \%$ & .40 \\
\hline $\begin{array}{l}\text { Preoperative aspirin (INN } \\
\text { acetylsalicylic acid) }\end{array}$ & $67.1 \%$ & $66.6 \%$ & .81 \\
\hline Preoperative statin & $61.2 \%$ & $59.8 \%$ & .50 \\
\hline $\begin{array}{l}\text { Preoperative clopidogrel bisulfate (INN } \\
\text { clopidogrel) }\end{array}$ & $22.1 \%$ & $22.3 \%$ & .92 \\
\hline Preoperative diuretics & $20.7 \%$ & $23.3 \%$ & .15 \\
\hline Crossclamp time (min, mean $\pm \mathrm{SD}$ ) & $39 \pm 22$ & $40 \pm 22$ & .31 \\
\hline Total bypass time (min, mean \pm SD) & $69 \pm 33$ & $72 \pm 35$ & .66 \\
\hline
\end{tabular}

Except as noted, numbers represent percentages of patients. Group A includes patients with negative change in serum creatinine $(\leq-0.1 \mathrm{mg} / \mathrm{dL})$; group $C$ includes patients with no change or subclinical increase in change in serum creatinine without acute kidney injury (change in serum creatinine $0-0.2 \mathrm{mg} / \mathrm{dL}$ with $<150 \%$ increase in serum creatinine from baseline).

30-day all-cause mortality differed between group A patients and group $\mathrm{B}$ or $\mathrm{C}$ patients. This analysis revealed that not only were patients with postoperative AKI (group B) at a significantly increased risk of 30-day all-cause mortality (OR, 14.69; 95\% CI, 6.42-33.62; $P<.01$ ), but also subclinical increase in serum creatinine (group C) was independently associated with an increased risk of 30-day allcause mortality (OR, 3.93; 95\% CI, 1.684-9.22; $P<.01$ ). ORs, corresponding $95 \%$ CIs, and associated $P$ values for all significant predictors of 30-day all-cause mortality for this analysis are presented in Figure 3. The c statistic for this analysis was 0.84 .
In an attempt to control further for selection bias related to change in serum creatinine and to determine whether a subclinical increase in serum creatinine was independently associated with an increased risk of 30-day allcause mortality, conditional logistic regression was also performed on a propensity score-matched cohort of 2042 patients between group A patients $(\mathrm{n}=1021)$ and group $C$ patients $(n=1021)$. Table 2 demonstrates that no significant differences existed in these variables between group A and group $\mathrm{C}$ patients. After controlling for propensity score, group $\mathrm{C}$ patients (with a subclinical increase in serum creatinine) were still found to be independently associated with an increased risk of 30-day all-cause mortality relative to group A patients (with a negative change in serum creatinine; $1.57 \%$ vs $0.39 \%$; OR, 4.13 ; $95 \%$ CI, $1.37-12.45$; $P=.01)$. This propensity score-matched analysis thus further supports our hypothesis that a subclinical postoperative change in serum creatinine may independently predict 30day all-cause mortality after $\mathrm{CABG}$ with $\mathrm{CPB}$.

\section{DISCUSSION}

Serum creatinine has long been used as a biomarker for $\mathrm{RF}$, and more recently it has been used for preoperative risk stratification..$^{1,2,9-11}$ Consistent with previous findings, our data demonstrate that both moderate and severe preoperative RI were associated with increased perioperative mortality after $\mathrm{CABG}$ with $\mathrm{CPB} \cdot{ }^{12,13}$ Few data exist to date, however, as to whether the postoperative change in serum creatinine serves as an independent biomarker for mortality after cardiac surgery in patients with varying degrees of preoperative RI. Because postoperative serum creatinine levels vary with baseline RF, it is important to assess change in serum creatinine as a biomarker across the spectrum of preoperative RF. We have now demonstrated that in the population undergoing primary isolated $\mathrm{CABG}$ with $\mathrm{CPB}$ postoperative change in serum creatinine is an independent predictor of 30-day all-cause postoperative mortality for patients with preoperative normal RF, mild $\mathrm{RI}$, or moderate RI, but not in patients with preoperative severe RI. Moreover, unlike previous studies that have focused solely on clinically significant positive changes in postoperative creatinine, we also demonstrated that a negative change in serum creatinine after CABG with $\mathrm{CPB}$ is associated with the lowest mortality and that even small, subclinical positive increases in change in serum creatinine that do not meet the AKI criteria as defined by $\mathrm{AKIN}^{6}$ or RI$\mathrm{FLE}^{7}$ criteria (change in serum creatinine $0-0.2 \mathrm{mg} / \mathrm{dL}$ with $<150 \%$ increase in creatinine from baseline) are associated with a 3.9-fold increase in 30-day all-cause postoperative mortality relative to a negative change in serum creatinine.

Although a small change in postoperative creatinine has been previously reported to be predictive of increased early mortality after cardiac surgery, earlier studies did not 


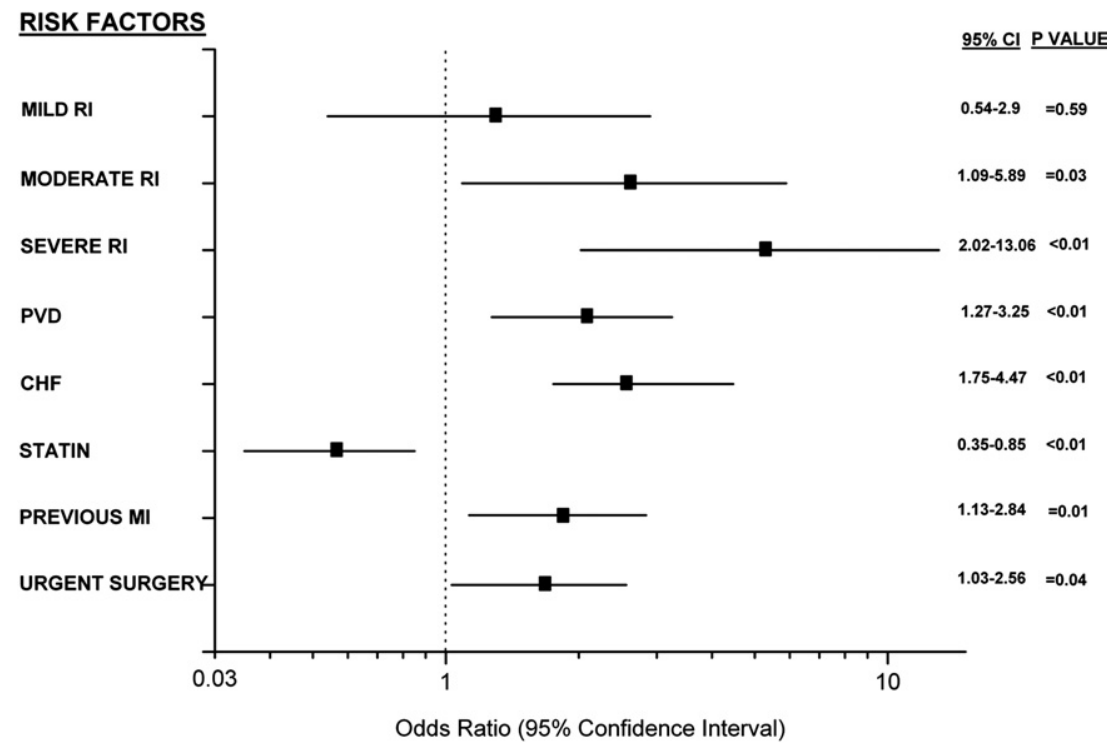

FIGURE 1. Multivariate logistic regression analysis of risk factors for 30-day all-cause mortality after coronary artery bypass grafting with cardiopulmonary bypass. $C I$, Confidence interval; $R I$, renal insufficiency; $P V D$, peripheral vascular disease; $C H F$, congestive heart failure; $M I$, myocardial infarction.

control for preoperative RF and were potentially confounded by inclusion of multiple types of cardiothoracic surgical procedures. ${ }^{3,4}$ In contrast to previous findings, we did not observe an increase in mortality as the change in serum creatinine became more negative, as had been previously reported. ${ }^{3,4}$ In addition, our study suggests that change in serum creatinine does not predict mortality in patients with severe preoperative RI. Although the underlying mechanism is not clear, we suspect that perioperative hemodilution and hydration after cardiac surgery may offset the changes in serum creatinine in patients with severe preoperative RI and high baseline creatinine levels. Nevertheless, the early diagnosis of AKI

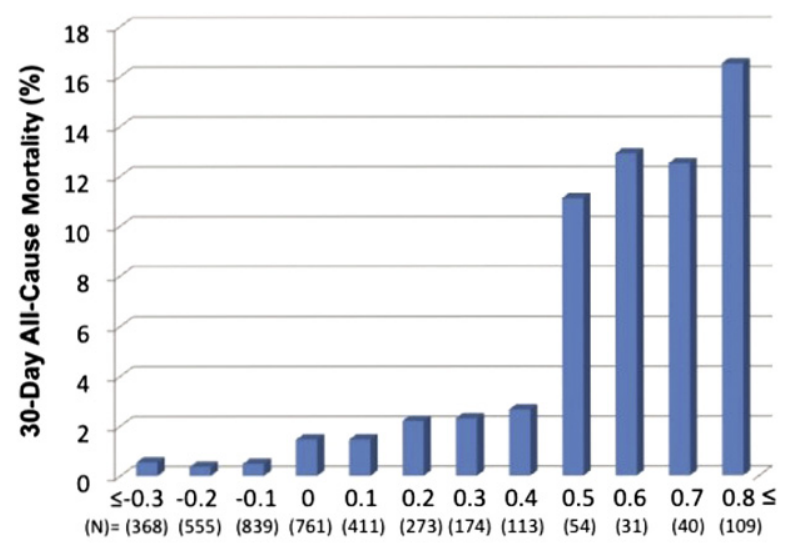

\section{$\Delta$ Creatinine (mg/dl)}

FIGURE 2. The 30-day all-cause mortalities for each change in serum creatinine ( $\triangle$ Creatinine) level in a combined group of patients with normal preoperative renal function and patients with mild and moderate preoperative renal insufficiency. may not be relevant in patients with severe preoperative RI, because those patients already have late-stage kidney damage and probably face irreversibly high perioperative mortality risk. $^{12,13}$

In our study, patients with a postoperative negative change in serum creatinine accounted for approximately $50 \%$ of the patient population who underwent CABG with CPB. It is interesting to note that these patients had the lowest postoperative mortality after the surgery. Although our study was not designed to delineate the pathophysiologic mechanisms responsible for changes in perioperative serum creatinine levels, we hypothesize that increases in postoperative creatinine (a positive change in serum creatinine) may indicate a state of global tissue hypoperfusion. Another mechanism that might explain why small postoperative changes in serum creatinine levels can independently predict increased 30-day all-cause mortality after CABG with CPB is that small rises in serum creatinine may be an early marker for evolving kidney damage, with progressive rises in serum creatinine levels indicative of a more serious global insult that affects multiple other end organs.

Serum creatinine is not protein bound, is physiologically inert, and is structurally stable without being further metabolized. Moreover, serum creatinine is produced solely through muscle creatinine dehydration and is eliminated through the kidneys. ${ }^{14}$ Thus serum creatinine may fulfill many criteria for a sensitive and reliable biomarker of RF after cardiac surgery. When patients have normal perfusion of the tissue and preserved kidney function after cardiac surgery with $\mathrm{CPB}$, variability of serum creatinine concentration may be minimal as a result of normal production and excretion of creatinine. In our study, the slight decreased 


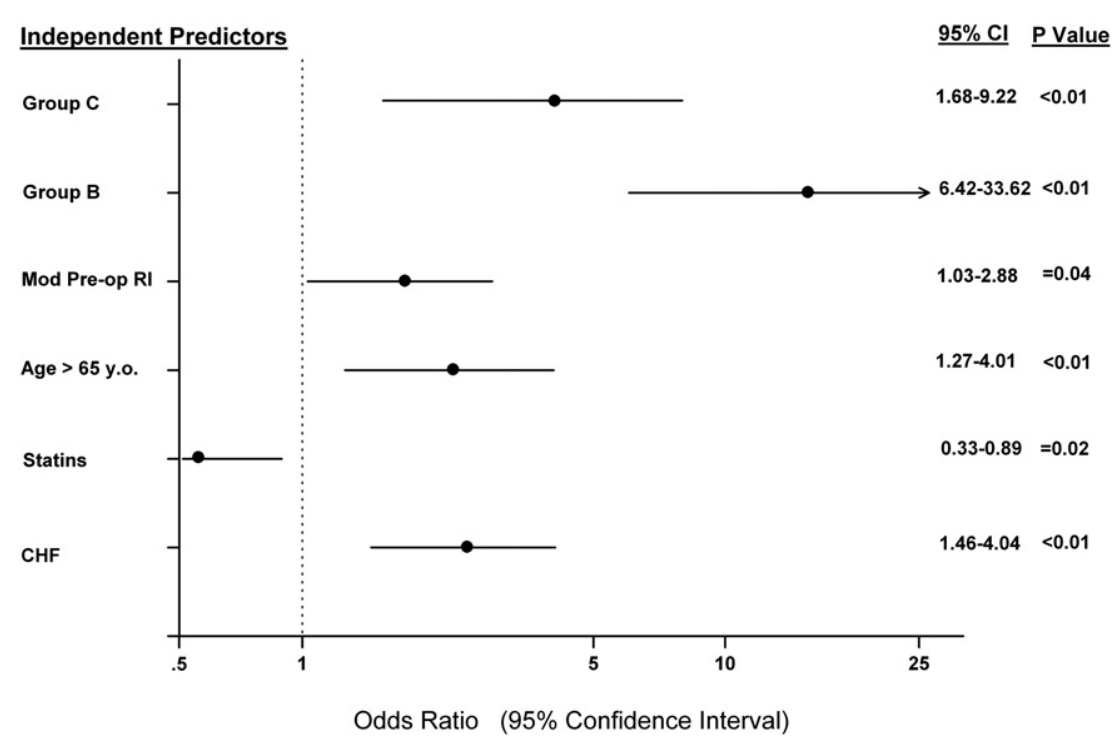

FIGURE 3. Multivariate analysis of 30-day all-cause mortality. Significant independent predictors along with their associated odds ratios and $95 \%$ confidence intervals $(C I s)$ are shown. Patients with subclinical increases in serum creatinine (group C) were independently associated with a higher risk of 30-day all-cause mortality. Mod Pre-op RI, Moderate preoperative renal insufficiency; $\mathrm{CHF}$, congestive heart failure.

levels of postoperative serum creatinine observed in approximate $50 \%$ of the patients likely reflect the effects of normal hemodilution and perioperative hydration after CABG with CPB. This may explain why those patients with negative changes in serum creatinine had the lowest mortality in our study. In contrast, a rise in serum creatinine may indicate decreased excretion of creatinine as a result of decreasing GFR or increased production of creatinine after prolonged skeleton muscle ischemia. ${ }^{15}$ A slight change in serum creatinine $(0-0.2 \mathrm{mg} / \mathrm{dL})$ after cardiac surgery with CPB may thus served to mark a group of patients with early stages of organ dysfunction or tissue hypoperfusion. At present, subclinical changes in serum creatinine $(0-0.2$ $\mathrm{mg} / \mathrm{dL}$ ) after cardiac surgery are often neglected with respect to clinical management. Our current findings therefore may highlight the importance of further investigation of serum creatinine as a sensitive and early perioperative marker to be used in outcome management after cardiac surgery.

In contrast to patients with subclinical changes in creatinine, patients with postoperative AKI (defined by $\mathrm{AKIN}^{6}$ or RIFLE $^{7}$ Criteria) were associated with a 14 fold increase in postoperative mortality (OR, 14.68 ; $95 \%$ CI, 6.42-33.62; $P<.01)$. This may reflect severe kidney or multiorgan injury, resulting in increased 30-day all cause mortality. Cardiac surgery-associated AKI is the second most common cause of AKI in critically ill patients, and it is well recognized as a risk factor for mortality after cardiac surgery. ${ }^{4,16,17}$ To date, however, there is no proven preventive strategy or treatment for AKI after cardiac surgery. It is therefore imperative to develop a biomarker for early diagnosis of AKI that will allow management to minimize postoperative morbidity and mortality. Historically, serum creatinine has been considered to be a relatively late biomarker for AKI, because there are known deficiencies with using serum creatinine levels during acute changes in RF. ${ }^{14,18,19}$ Recently, several novel biomarkers have been developed to improve the sensitivity and specificity of the early diagnosis of AKI. Neutrophil gelatinase-associated lipocalin, kidney injury molecule 1, and interleukin 18 are all novel biomarkers currently being investigated to improve our ability to diagnose AKI in its earliest stages. ${ }^{20-23}$ These new biomarkers may be capable of detecting AKI within hours of the initial kidney injury and have specifically been examined in patients undergoing cardiac surgery, with promising results. ${ }^{20,22,23}$ Nevertheless, our results suggest that irrespective of serum creatinine's utility as a marker for acute changes in RF, serum creatinine is a sensitive and significant biomarker for prediction of 30-day allcause mortality in patients undergoing CABG with CPB.

Although this study contributes to the literature regarding biomarkers and outcomes after $\mathrm{CABG}$ with $\mathrm{CPB}$, there are several limitations that must be considered. First, this was a retrospective cohort study, and enrollment was neither prospective nor randomized. We believe that it is important to perform a prospectively designed study to investigate perioperative creatinine kinetics in patients with normal $\mathrm{RF}$ and varying levels of preoperative RI undergoing CABG with CPB. Second, although appropriate statistical models were used in analyzing the data, there still remains the possibility that unmeasured factors may have affected the outcomes. Third, serum creatinine levels were only followed for the first 48 hours postoperatively, and this limited 
time frame may have missed serum creatinine changes that happened beyond the first 48 hours after surgery but nonetheless may have affected 30-day all cause mortality.

In conclusion, serum creatinine changes in the perioperative period may be a sensitive biomarker for predicting 30day all cause mortality in patients undergoing CABG with $\mathrm{CPB}$. Importantly, even small subclinical positive increases in serum creatinine that do not meet the AKI criteria as defined by $\mathrm{AKIN}^{6}$ or $\mathrm{RIFLE}^{7}$ criteria were associated with a 3.9 fold increase in 30-day all-cause postoperative mortality. Thus subclinical serum creatinine changes after CABG with CPB may provide an early warning of the need for clinical intervention. Future prospective studies are needed to evaluate the effectiveness of clinical interventions made on the basis of serum creatinine changes after $\mathrm{CABG}$ with $\mathrm{CPB}$.

We thank Kathy Brient, manager of Laboratory Information Systems at St Luke's Episcopal Hospital, Houston, Tex, for her assistance in collecting creatinine data.

\section{References}

1. Geissler HJ, Hölzl P, Marohl S, Kuhn-Régnier F, Mehlhorn U, Südkamp M, et al. Risk stratification in heart surgery: comparison of six score systems. Eur J Cardiothorac Surg. 2000;17:400-6.

2. Shahian DM, O'Brien SM, Filardo G, Ferraris VA, Haan CK, Rich JB, et al. The Society of Thoracic Surgeons 2008 cardiac surgery risk models: part 1-coronary artery bypass grafting surgery. Ann Thorac Surg. 2009;88(1 Suppl):S2-22.

3. Lassnigg A, Schmidlin D, Mouhieddine M, Bachmann LM, Druml W, Bauer P, et al. Minimal changes of serum creatinine predict prognosis in patients after cardiothoracic surgery: a prospective cohort study. J Am Soc Nephrol. 2004;15: 1597-605.

4. Lassnigg A, Schmid ER, Hiesmayr M, Falk C, Druml W, Bauer P, et al. Impact of minimal increases in serum creatinine on outcome in patients after cardiothoracic surgery: do we have to revise current definitions of acute renal failure? Crit Care Med. 2008;36:1129-37.

5. Swaminathan M, Hudson CC, Phillips-Bute BG, Patel UD, Mathew JP, Newman MF, et al. Impact of early renal recovery on survival after cardiac surgery-associated acute kidney injury. Ann Thorac Surg. 2010;89:1098-104.

6. Mehta RL, Kellum JA, Shah SV, Molitoris BA, Ronco C, Warnock DG, et al. Acute Kidney Injury Network: report of an initiative to improve outcomes in acute kidney injury. Crit Care. 2007;11:R31.

7. Bellomo R, Ronco C, Kellum JA, Mehta RL, Palevsky P, Acute Dialysis Quality Initiative workgroup. Acute renal failure - definition, outcome measures, animal models, fluid therapy and information technology needs: the Second Interna- tional Consensus Conference of the Acute Dialysis Quality Initiative (ADQI) Group. Crit Care. 2004;8:R204-12.

8. Levey AS, Coresh J, Balk E, Kausz AT, Levin A, Steffes MW, et al. National Kidney Foundation practice guidelines for chronic kidney disease: evaluation, classification, and stratification. Ann Intern Med. 2003;139:137-47.

9. Miceli A, Bruno VD, Capoun R, Romeo F, Angelini GD, Caputo M. Occult renal dysfunction: a mortality and morbidity risk factor in in coronary artery bypass grafting surgery. J Thorac Cardiovasc Surg. 2011;141:771-6.

10. Najafi M, Goodarzynejad H, Karimi A, Ghiasi A, Soltaninia H, Marzban M, et al. Is preoperative serum creatinine a reliable indicator of outcome in patients undergoing coronary artery bypass surgery? J Thorac Cardiovasc Surg. 2009;137:304-8.

11. Jyrala A, Weiss RE, Jeffries RA, Kay GL. Effect of mild renal dysfunction (s-crea $1.2-2.2 \mathrm{mg} / \mathrm{dl}$ ) on presentation characteristics and short-and long-term outcomes of on-pump cardiac surgery patients. Interact Cardiovasc Thorac Surg. 2010;10: 777-82.

12. Cooper WA, O'Brien SM, Thourani VH, Guyton RA, Bridges CR, Szczech LA, et al. Impact of renal dysfunction on outcomes of coronary artery bypass surgery: results from the Society of Thoracic Surgeons National Adult Cardiac Database. Circulation. 2006;113:1063-70.

13. Yeo KK, Li Z, Yeun JY, Amsterdam E. Severity of chronic kidney disease as a risk factor for operative mortality in nonemergent patients in the California coronary artery bypass graft surgery outcomes reporting program. Am J Cardiol. 2008;101:1269-74.

14. Perrone RD, Madias NE, Levey AS. Serum creatinine as an index of renal function: new insights into old concepts. Clin Chem. 1992;38:1933-53.

15. Sorlie D, Huseby NE, Kluge T. Eschaemia during arterial reconstructive surgery. Biochemical changes as reflected in popliteal vein samples. Scand J Thorac Cardiovasc Surg. 1977;11:151-8.

16. Karkouti K, Wijeysundera DN, Yau TM, Callum JL, Cheng DC, Crowther M, et al. Acute kidney injury after cardiac surgery: focus on modifiable risk factors. Circulation. 2009;119:495-502.

17. Uchino S, Kellum JA, Bellomo R, Doig GS, Morimatsu H, Morgera S, et al. Acute renal failure in critically ill patients: a multinational, multicenter study. JAMA. 2005;294:813-8.

18. Cruz DN, Ronco C, Katz N. Neutrophil gelatinase-associated lipocalin: a promising biomarker for detecting cardiac surgery-associated acute kidney injury. J Thorac Cardiovasc Surg. 2010;139:1101-6.

19. Nguyen MT, Devarajan P. Biomarkers for the early detection of acute kidney injury. Pediatr Nephrol. 2008;23:2151-7.

20. Bennett M, Dent CL, Ma Q, Dastrala S, Grenier F, Workman R, et al. Urine NGAL predicts severity of acute kidney injury after cardiac surgery: a prospective study. Clin J Am Soc Nephrol. 2008;3:665-73.

21. Han WK, Bailly V, Abichandani R, Thadhani R, Bonventre JV. Kidney Injury Molecule-1 (KIM-1): a novel biomarker for human renal proximal tubule injury. Kidney Int. 2002;62:237-44.

22. Parikh CR, Mishra J, Thiessen-Philbrook H, Dursun B, Ma Q, Kelly C, et al. Urinary IL-18 is an early predictive biomarker of acute kidney injury after cardiac surgery. Kidney Int. 2006;70:199-203.

23. Wagener G, Gubitosa G, Wang S, Borregaard N, Kim M, Lee HT. Urinary neutrophil gelatinase-associated lipocalin and acute kidney injury after cardiac surgery. Am J Kidney Dis. 2008;52:425-33. 
TABLE E1. Criteria for acute kidney injury

\section{Serum creatinine and}

GFR criteria

Urinary output criteria

\begin{tabular}{|c|c|c|}
\hline \multicolumn{3}{|l|}{ AKIN stage } \\
\hline 1 & $\begin{array}{l}\text { Increase in serum creatinine } \geq 0.3 \mathrm{mg} / \mathrm{dL} \text { or increase } \geq 150 \%-200 \% \\
\text { from baseline }\end{array}$ & $<0.5 \mathrm{~mL} /(\mathrm{kg} \cdot \mathrm{h})$ for $\geq 6 \mathrm{~h}$ \\
\hline 2 & Increase in serum creatinine $>200 \%-300 \%$ from baseline & $<0.5 \mathrm{~mL} /(\mathrm{kg} \cdot \mathrm{h})$ for $\geq 12 \mathrm{~h}$ \\
\hline 3 & $\begin{array}{l}\text { Increase in serum creatinine }>300 \% \text { from baseline or } \geq 4.0 \mathrm{mg} / \mathrm{dL} \text { with } \\
\text { an acute rise }>0.5 \mathrm{mg} / \mathrm{dL}\end{array}$ & $\begin{array}{l}<0.3 \mathrm{~mL} /(\mathrm{kg} \cdot \mathrm{h}) \geq 24 \text { hours or } \\
\text { anuria } \geq 12 \text { hours }\end{array}$ \\
\hline \multicolumn{3}{|l|}{ RIFLE criteria } \\
\hline Risk & 1.5 -fold increase in serum creatinine or $>25 \%$ decrease in GFR & $<0.5 \mathrm{~mL} /(\mathrm{kg} \cdot \mathrm{h})$ for $\geq 6 \mathrm{~h}$ \\
\hline Injury & 2 -fold increase in serum creatinine or $>50 \%$ decrease in GFR & $<0.5 \mathrm{~mL} /(\mathrm{kg} \cdot \mathrm{h})$ for $\geq 12 \mathrm{~h}$ \\
\hline Failure & $\begin{array}{l}3 \text {-fold increase in serum creatinine or serum creatinine } \geq 4 \mathrm{mg} / \mathrm{dL} \text { or } \\
75 \% \text { decrease in GFR }\end{array}$ & $\begin{array}{l}<0.3 \mathrm{~mL} /(\mathrm{kg} \cdot \mathrm{h}) \text { for } \geq 24 \mathrm{~h} \text { or } \\
\text { anuria for } \geq 12 \mathrm{~h}\end{array}$ \\
\hline Loss & Total loss of kidney function for $\geq 4 \mathrm{wk}$ & \\
\hline End-stage kidney disease & End-stage kidney disease for $\geq 3 \mathrm{mo}$ & \\
\hline
\end{tabular}
end-stage kidney disease (criteria for the diagnosis of acute kidney injury adopted from Bellomo and associates ${ }^{7}$ ). 